\title{
Cognitive effectiveness of olanzapine and risperidone in first-episode psychosis
}

\author{
Manuel J. Cuesta, Elena García de Jalón, M. Soledad Campos and Victor Peralta
}

\section{Background}

Cognitive impairment in schizophrenia-spectrum disorders is highly prevalent and notably influences functional outcomes.

\author{
Aims \\ To characterise the cognitive effectiveness of second- \\ generation antipsychotic drugs.
}

\section{Method}

One hundred consecutive and previously unmedicated patients with first-episode schizophrenia-spectrum disorders were admitted. Seventy-seven completed baseline, 1-month and 6-month psychopathological and neuropsychological assessments. Patients were randomised to risperidone or olanzapine treatment. Four final treatment allocation groups were defined since patients continued treatment in their normal setting: risperidone, olanzapine, mixed and no-antipsychotic groups.

\section{Results}

There were no differences in cognitive effectiveness between the four treatment groups. Reliable change index methods demonstrated that nearly a half of patients showed an improvement in Global Cognitive Score at the 6-month assessment. Improvement on the neuropsychological tests ranged from 17 to $54 \%$.

A strong predictor of cognitive response was poor performance on baseline neuropsychological tests; response was moderately influenced by a low premorbid scholastic performance and $\mathrm{IQ}$.

\section{Conclusions}

Cognitive improvement related to second-generation antipsychotic drugs appeared within the first 4 weeks of treatment and persisted at 6 months irrespective of treatment group. Greater cognitive dysfunction at baseline and lower premorbid cognitive background predicted cognitive improvement in our sample.

\section{Declaration of interest}

None.
Cognitive impairment is a prevalent feature in patients with schizophrenia ${ }^{1-5}$ that greatly influences functional outcomes. ${ }^{6,7}$ Both global deficit and impairments in attention, memory and executive functions are commonly found in schizophrenia.

A renewed interest in the amelioration of cognitive deficits of schizophrenia arose with the new antipsychotic drugs. Earlier reviews suggested that first-generation antipsychotic drugs did not improve cognitive performance in schizophrenia, ${ }^{8-13}$ although studies concluded that low doses of typical antipsychotics seem to have favourable cognitive effects. ${ }^{14-18}$ Moreover, two recent contributions reduce the strength of the argument for cognitive efficacy of antipsychotic drugs. First, the CATIE study concluded that the cognitive improvement related to either first- or second-generation antipsychotics was significant, but smaller than previously reported. ${ }^{17}$ Second, it was recently suggested that part of this improvement in patients with first-episode schizophrenia was similar to the practice effect observed in healthy controls. ${ }^{19}$

The present study was a naturalistic, randomly assigned and non-commercially funded study aimed at assessing the cognitive outcome at 6 months in a sample of drug-naive patients with first-episode psychosis. The primary goal was to compare cognitive function between four treatment conditions: patients receiving either risperidone or olanzapine; patients who changed their initial atypical antipsychotic; and patients who did not receive antipsychotics in the last 3 months of the study. As a secondary goal, this study aimed to investigate individual prognostic indicators of a good cognitive response irrespective of treatment group.

\section{Method}

\section{Participants}

A total of 100 consecutive, drug-naive patients with first-episode psychosis were evaluated. Inclusion criteria were: (a) patients aged 16-65 years

(b) an acute episode at study intake that met DSM-IV-TR ${ }^{20}$ criteria for schizophrenia and other psychotic disorders

(c) no previous exposure to antipsychotics

(d) provided written informed consent and able to take part in neuropsychological assessment.

Patients with a history of serious medical or neurological disease, head injury, intellectual disability or drug dependence were excluded from the study.

All study aims and procedures were fully explained to participants and their families before they signed a written consent form; the study was approved by the institutional review board.

\section{Study design and procedures}

This was a longitudinal and naturalistic study, which comprised comprehensive psychopathological and neuropsychological assessments at three points: baseline, 1-month and 6-month follow-up. All patients underwent the Comprehensive Assessment of Symptoms and History interview. ${ }^{21}$ A DSM-IV-TR diagnosis was reached by clinical consensus between the two senior researchers (M.J.C. and V.P.).

Two psychiatrists (E.G.J. and M.S.C.) assessed the psychopathological and cognitive status of patients in such a way that each was masked to the assessment of the other and to the treatment received by patients. Good interrater reliability coefficients for psychopathological assessments $(\kappa=0.80-0.98)$ were achieved by the two psychiatrists.

Once baseline assessments were completed on the first day of admission, participants were randomly assigned to receive either risperidone $(n=56)$ or olanzapine $(n=44)$ treatment. Patients initially received a low dose $(2.5 \mathrm{mg}$ for risperidone, $5 \mathrm{mg}$ for 
olanzapine), which was gradually titrated up while active symptoms were present. Patients were followed in their natural treatment environment and treatment decisions after initial randomisation were made by treating psychiatrists.

Of the 100 patients, 23 withdrew during the course of the study (11 and 12 individuals at 1-month and 6-month assessments respectively) (Fig. 1). Final drug allocation groups were as follows: risperidone group, $n=29$; olanzapine group, $n=22$; mixed group (those patients who needed to change their initial antipsychotic to another atypical antipsychotic), $n=16$; and no-antipsychotic group (those patients who did not receive antipsychotic drugs in the last 3 months of follow-up), $n=10$.

Doses of the atypical antipsychotics were transformed to chlorpromazine equivalents $(\mathrm{mg}){ }^{22}$ Patients received either biperidene or benzodiazepines if needed by indication of the treating psychiatrists.

Drug adherence was assured by collecting information independently from patients, families and the attending psychiatrist at every point of assessment. Surveillance by close relatives is one of most accurate methods of measuring adherence. $^{23}$

\section{Neuropsychological assessment}

Participants were assessed by means of a comprehensive neuropsychological battery measuring attention, executive function, information processing, and memory. Neuropsychological tests included: Verbal Fluency ${ }^{24}$ (number of animals evoked in $1 \mathrm{~min}$ ); Trail Making Test - form B ${ }^{24}$ (number of seconds to complete the task); Wechsler Memory Scale (WMS); ${ }^{25}$ and four tasks of the COGLAB computerised neuropsychological battery: ${ }^{26,27}$ a reaction time task (that included Redundancy-Associated Deficit (RAD), a vigilance and span of apprehension task (Asarnow's test, which included Total Hits and Total False Alarms), a visual backward masking task (iconic memory test), and the Wisconsin Card Sorting Test (WCST; Perseverative Errors and Total Trials).

Exploratory factor analyses of the 14 cognitive measures at each assessment point were done to obtain a Global Cognitive Score (GCS) and to normalise different scales of measurements. Exploratory factor analyses resulted in four factors (eigenvalue $=1$ ), although an inspection of the three Scree test plots revealed that only one factor achieved the greater percentage of explained variance. Thus, reduction to a one-factor solution was carried out and baseline, 1-month and 6-month GCS variables were saved. Oblimin rotation was chosen to allow factors to be correlated, as it occurs usually among cognitive measures. ${ }^{28}$

General IQ was ascertained by means of the Spanish version of a non-verbal IQ test (TONI-2 Test). ${ }^{29}$

\section{Statistical analysis}

To compare demographic and clinical characteristics between groups, one-way repeated measures ANOVA and chi-squared test were applied. Logarithmic transformation or $z$-transformations were applied to non-normally distributed variables.

Testing occasion was the within-group factor (baseline, 1 month and 6 months) and treatment assignment was the between-group factor (risperidone, olanzapine, mixed and no-antipsychotic groups). Repeated measures ANCOVA was also performed for each cognitive variable using baseline neuropsychological assessments, biperidene and antipsychotic mean doses (chlorpromazine equivalents in $\mathrm{mg}$ ) as covariates. Tukey's Honestly Significant Difference test was performed for post hoc analysis between diagnostic groups.

We also calculated two forms of the reliable change index $(\mathrm{RCI}),{ }^{30}$ which is a group of statistical techniques used in many areas of medicine to help determine when an individual's performance on a neuropsychological test has changed from a previous assessment with the same test. The index provides

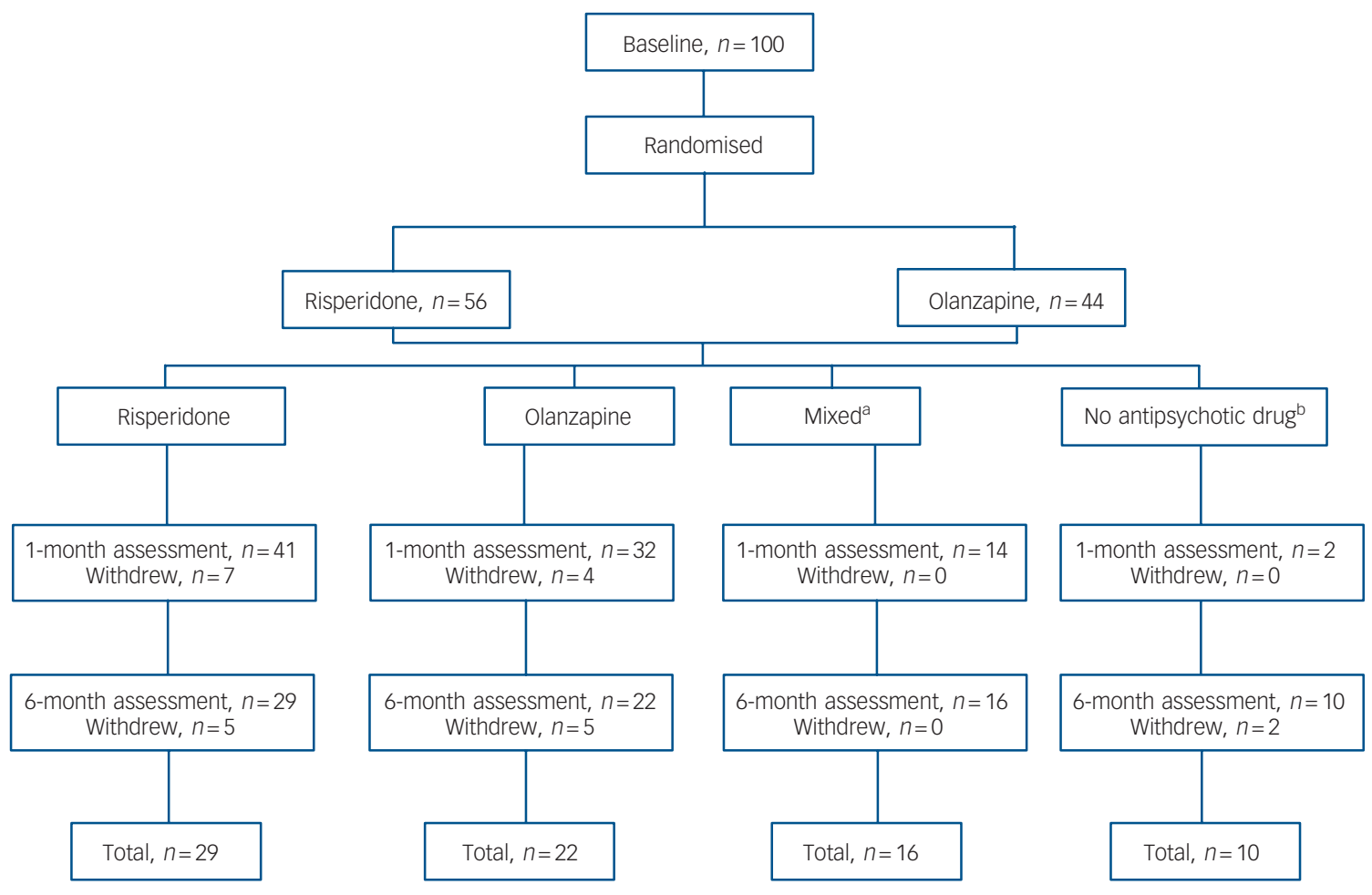

Fig. 1 Flow of participants through the study. 
information about whether people have changed sufficiently that the change is unlikely to be due to simple measurement unreliability. Formulas for RCI-simple (RCI-s) and RCI-practice (RCI-p) are shown in the online supplement to this paper.

\section{Results}

\section{Demographic and clinical characteristics of treatment groups}

No differences in clinical or epidemiological variables at baseline were found between those patients who withdrew $(n=23,23 \%)$ and those who completed the study $(n=77,77 \%)$ except for years of education $(t=2.36$, d.f. $=98, P<0.020)$ (Table 1$)$. The subsequent results refer to those who completed the three assessments $(n=77)$.

The four treatment groups did not differ in most epidemiological, clinical and diagnostic variables. However, the risperidone group had significantly higher scores for psychotic syndrome than the olanzapine group; the no-antipsychotic group had significantly higher scores than the risperidone group for depressive syndrome; and the risperidone and mixed groups showed significantly higher scores for disorganisation syndrome than the olanzapine group at baseline (online Table DS1). Patients in the risperidone group received higher antipsychotic doses at 6month but not at 1-month assessment and they were treated more often with anticholinergic drugs $(37.93 \%)$ than either the mixed $(18.75 \%)$ or olanzapine and no-antipsychotic groups (0\%) (Table 2).

\section{Neuropsychological test results}

No significant main effects on neuropsychological tests and on the GCS were found for any of the four groups. Cognitive performance showed significant improvement over time on most neuropsychological tests irrespective of the treatment group, with the exception of performance on three tasks: reaction time, RAD and Asarnow Total False Alarms (Table 3). The mixed group showed greater improvement than the other three groups on WMS Associated Learning (group $\times$ time interaction: $F=2.63$, d.f. $=3.63, P=0.044$ ).

After including antipsychotic and biperidene doses at the 6month point with baseline neuropsychological results as covariates on repeated measures ANCOVA analyses, most effects for time vanished. Only the effects for time on WCST Total Trials $(F=6.29$, d.f. $=1, P=0.015)$ and Asarnow Total Hits $(F=12.47$, d.f. $=1, P=0.001)$ remained statistically significant.

The significant findings of both ANOVA and ANCOVA did not exceed the required $P$-value level of the Bonferroni correction $(P=0.003$, for 16 sets of repeated measures of ANOVA or ANCOVA), except for Asarnow Total Hits.

\section{Reliable change index scores}

Reliable change indices for the whole sample demonstrated great variation in individual patterns over time across neuropsychological tests, although both indices (simple and practice) showed similar scores. Specifically, the percentages of patients who improved on neuropsychological tests and GCS ranged from $17.33 \%$ on Asarnow False Alarms to $54.54 \%$ on Verbal Fluency (Table 3).

The RCI-s and RCI-p results for the GCS demonstrated that $35(47.29 \%)$ and $33(45.83 \%)$ patients respectively showed a statistically meaningful improvement (or reliable improvement) and that $39(52.70 \%)$ and $38(52.77 \%)$ patients respectively displayed a lower change than expected at 6-month follow-up. However, there were no individual patients performing below their own baseline performance at the 6-month assessment on any cognitive measures.

Reliable worsening and stable patterns should be interpreted with caution since they do not represent patients definitively

\begin{tabular}{|c|c|c|c|c|c|c|}
\hline & $\begin{array}{l}\text { Risperidone } \\
\quad(n=29)\end{array}$ & $\begin{array}{l}\text { Olanzapine } \\
(n=22)\end{array}$ & $\begin{array}{l}\text { Mixed } \\
(n=16)\end{array}$ & $\begin{array}{l}\text { No antipsychotic } \\
\text { drug }(n=10)\end{array}$ & $\begin{array}{c}\text { Total } \\
(n=77)\end{array}$ & Statistic $(P)$ \\
\hline \multicolumn{7}{|l|}{ Gender } \\
\hline Male & 22 & 16 & 9 & 6 & 53 & \multirow[t]{2}{*}{$\chi^{2}=2.37(0.5)$} \\
\hline Female & 7 & 6 & 7 & 4 & 24 & \\
\hline Age, years: mean (s.d.) & $26.7(7.44)$ & $32.73(11.8)$ & $30.13(10.86)$ & $34.10(8.86)$ & $30.09(10)$ & $F=2.27(0.087)^{a}$ \\
\hline Age at onset, years: mean (s.d.) & $24.99(7.57)$ & $31.5(11.8)$ & $26.63(9.17)$ & $29.89(9.93)$ & $27.83(9.78)$ & $F=2.16(0.099)^{a}$ \\
\hline Duration of illness, years: mean (s.d.) & $0.84(1.47)$ & $0.61(0.9)$ & $1.74(3.12)$ & $2.10(3.65)$ & $1.13(2.2)$ & $F=1.67(0.179)^{a}$ \\
\hline Years of education, mean (s.d.) & $13.83(3.52)$ & $15(4.61)$ & $12.38(4.36)$ & $14.30(3.23)$ & $13.92(4.04)$ & $F=1.35(0.263)^{a}$ \\
\hline Parentś years of education, mean (s.d.) & $8.83(3.38)$ & $7.76(2.27)$ & $7.03(1.81)$ & $8.20(3.73)$ & $8.07(2.90)$ & $F=1.46(0.233)^{a}$ \\
\hline \multicolumn{7}{|l|}{ Scholastic performance, ${ }^{\mathrm{b}} n(\%)$} \\
\hline Excellent & $3(10)$ & $1(5)$ & 0 & $1(10)$ & $5(6)$ & \multirow[t]{5}{*}{$\chi^{2}=13.56(0.330)$} \\
\hline Good & $3(10)$ & $4(18)$ & $2(13)$ & $3(30)$ & $12(16)$ & \\
\hline Medium & $12(41)$ & $10(45)$ & $4(25)$ & $4(40)$ & $30(39)$ & \\
\hline Low & $8(28)$ & $6(27)$ & $10(63)$ & $1(10)$ & $25(32)$ & \\
\hline Failing & $3(10)$ & $1(5)$ & 0 & $1(10)$ & $5(6)$ & \\
\hline GAF-P, mean (s.d.) & $76.07(17.71)$ & $80.14(12.54)$ & $73.94(21.45)$ & $82.30(17.04)$ & $77.60(17.11)$ & $F=0.72 ;(0.540)^{a}$ \\
\hline Current IQ (TONI-2), mean (s.d.) & $96.9(17.85)$ & $92.5(18.94)$ & $96.06(18.35)$ & $99.10(20.74)$ & $95.75(18.41)$ & $F=0.37 ;(0.776)^{a}$ \\
\hline \multicolumn{7}{|l|}{ DSM-IV-TR diagnosis, $n$ (\%) } \\
\hline Schizophrenia & $16(55)$ & $6(27)$ & $7(44)$ & $4(40)$ & $33(43)$ & \multirow[t]{6}{*}{$\chi^{2}=21.47 ;(0.122)$} \\
\hline Schizoaffective disorder & $1(3)$ & $1(5)$ & $2(13)$ & $2(20)$ & $6(8)$ & \\
\hline Brief psychotic disorder & $6(21)$ & $7(32)$ & $4(25)$ & $1(10)$ & $18(23)$ & \\
\hline Schizophreniform disorder & $6(21)$ & $3(14)$ & $3(19)$ & 0 & $12(16)$ & \\
\hline Delusional disorder & 0 & $4(19)$ & 0 & $2(20)$ & $6(8)$ & \\
\hline Atypical psychosis & 0 & $1(5)$ & 0 & $1(10)$ & $2(3)$ & \\
\hline Benzodiazepines, n (\%) & $22(76)$ & $16(73)$ & $13(81)$ & $9(90)$ & $60(78)$ & \\
\hline
\end{tabular}


Table 2 Clinical and pharmacological characteristics of the sample at 1-month and 6-month assessment

\begin{tabular}{|c|c|c|c|c|c|c|}
\hline & $\begin{array}{l}\text { Risperidone } \\
\quad(n=29)\end{array}$ & $\begin{array}{l}\text { Olanzapine } \\
\qquad(n=22)\end{array}$ & $\begin{array}{l}\text { Mixed } \\
(n=16)\end{array}$ & $\begin{array}{l}\text { No antipsychotic } \\
\text { drug }(n=10)\end{array}$ & $\begin{array}{c}\text { Total } \\
(n=77)\end{array}$ & Statistic $(P)$ \\
\hline \multicolumn{7}{|l|}{ 1-month assessment } \\
\hline $\begin{array}{l}\text { Chlorpromazine equivalent dose, mg: } \\
\text { mean (s.d.) }\end{array}$ & 303.44 (136.23) & $215.90(96.83)$ & $290.62(174.13)$ & $227.50(134.08)$ & $265.90(138.30)$ & $F=2.19(0.096)^{a}$ \\
\hline \multicolumn{7}{|l|}{ Biperidene } \\
\hline Dose, mg: mean (s.d.) & $3.33(1.15)$ & 0 & 0 & 0 & $3.33(1.15)$ & $F=1.60(0.195)^{a}$ \\
\hline Patients, $n(\%)$ & $3(10)$ & 0 & 0 & 0 & $3(4)$ & \\
\hline Benzodiazepines, $n$ (\%) & $29(100)$ & $17(77)$ & $16(100)$ & $9(90)$ & $71(92)$ & \\
\hline \multicolumn{7}{|l|}{ 6-month assessment } \\
\hline \multicolumn{7}{|l|}{ DSM-IV-TR diagnosis, $n$ (\%) } \\
\hline Schizophrenia & $23(79)$ & $10(45)$ & $10(63)$ & $4(40)$ & $47(61)$ & $\chi^{2}=26.12(0.097)$ \\
\hline Schizoaffective disorder & $2(7)$ & $2(9)$ & $3(19)$ & $2(20)$ & $9(12)$ & \\
\hline Acute psychosis & $3(10)$ & $5(23)$ & $2(13)$ & $1(10)$ & $11(14)$ & \\
\hline Schizophreniform disorder & $1(3)$ & $1(5)$ & $1(6)$ & 0 & $3(4)$ & \\
\hline Delusional disorder & 0 & $4(18)$ & 0 & $2(20)$ & $6(8)$ & \\
\hline Atypical psychosis & 0 & 0 & 0 & $1(10)$ & 0 & \\
\hline $\begin{array}{l}\text { Chlorpromazine equivalent dose, } \\
\text { mg: mean (s.d.) }\end{array}$ & $\begin{array}{c}212.93 \\
(143.24)\end{array}$ & $\begin{array}{l}145.45 \\
(72.22)\end{array}$ & $\begin{array}{c}288.09 \\
(334.14)\end{array}$ & 0 & $\begin{array}{c}206.28 \\
(190.06)\end{array}$ & $F=6.04(0.001)^{a, b}$ \\
\hline \multicolumn{7}{|l|}{ Biperidene } \\
\hline Dose, mg: mean (s.d.) & $3.63(0.81)$ & 0 & $4(0)$ & 0 & $3.71(0.72)$ & $F=5.02(0.003)^{a, c}$ \\
\hline Patients, $n(\%)$ & $11(38)$ & 0 & $3(19)$ & 0 & $14(18)$ & \\
\hline Benzodiazepines, $n$ (\%) & $26(90)$ & $21(95)$ & $14(88)$ & 0 & $71(92)$ & \\
\hline \multicolumn{7}{|c|}{$\begin{array}{l}\text { a. One-way ANOVA. } \\
\text { b. Risperidone>no antipsychotic drug; mixed }>\text { no antipsychotic drug. } \\
\text { c. Risperidone>olanzapine, no antipsychotic drug. }\end{array}$} \\
\hline
\end{tabular}

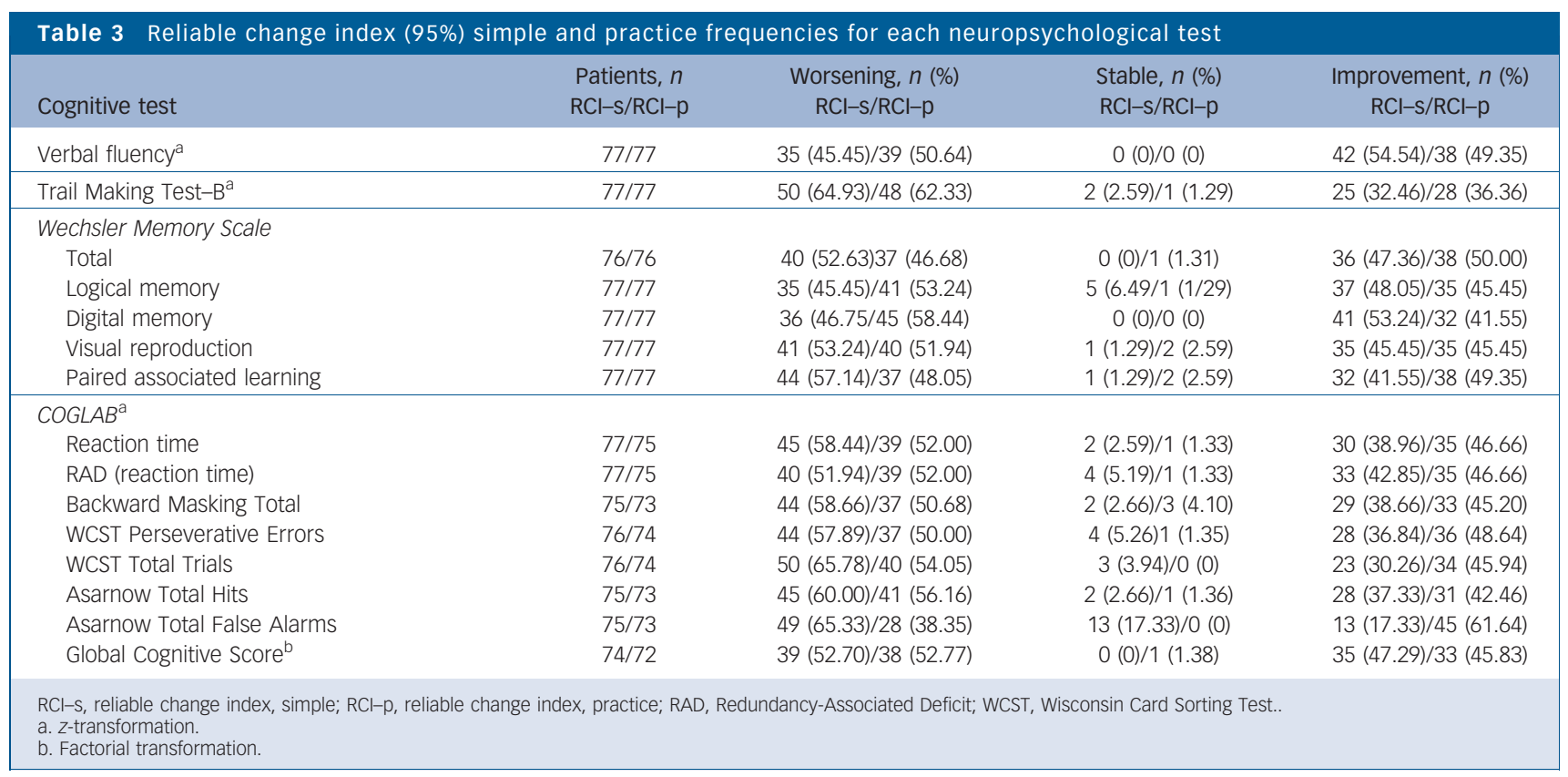

showing a deteriorating outcome, rather those patients who did not reach significant statistical changes as shown in online Fig. DS1.

To characterise the cognitive improvement of our patients, two sets of stepwise regression procedures were set for demographic and clinical variables in which the indices of neuropsychological tests and of GCS were introduced as 'dummy' dependent variables (improvement $v$. stable and no-improvement patients) (see footnote of online Table DS2 for a description of variables entered into the regression analyses). Moreover, in order to gain greater insight into patients' cognitive performance, it was necessary to account for both ceiling effects of cognitive measures and for patients' performance within normal ranges on neuropsychological tests by including baseline performance on each test and baseline GCS together with the above demographic and clinical variables for both RCI-s and RCI-p.

Patients with a cognitive response were strongly influenced by poor performance on neuropsychological tests at baseline (online Table DS2). The premorbid scholastic performance and current IQ were moderate predictors of cognitive improvement; high baseline psychopathological scores (disorganisation and psychotic syndrome scores), treatment variables (lower 6-month chlorpromazine equivalent doses) and 6-month DSM-IV-TR diagnosis were slight, but also significant predictors. Treatment status was not included in these patients' profiles in the regression analyses. 


\section{Discussion}

In the present study, we followed the treatment effects of atypical antipsychotic drugs on neurocognitive performance in a drugnaive patient sample with first-episode schizophrenia-spectrum disorders over 6 months in a naturalistic setting.

Three main conclusions can be drawn from this study. First, no differences in cognitive effectiveness were found between the four treatment groups. Second, 30\% of the total sample showed an improvement in GCS at 6 months and showed improvement on the 14 neuropsychological tests ranging from 17 to $54 \%$. Finally, the clinical profile at the individual level was strongly influenced by poor cognitive performance at baseline and moderately influenced by low premorbid scholastic performance and low IQ. Female gender, young age and low antipsychotic doses at the 6-month assessment also contributed marginally to a better cognitive improvement profile at the individual level.

Levels of cognitive impairment and rates of global cognitive improvement in our patients were in keeping with previous studies at initial disease presentation. ${ }^{31-34}$ Our results can also be applied to non-drug-naive patients with first-episode psychosis since no differences were evident between studies comparing drug-naive and non-naive patients in first-episode psychosis. ${ }^{35,36}$

It is usually taken for granted that cognitive improvement is a direct effect of antipsychotic drugs; however, any longitudinal cognitive change (either improvement or worsening) in schizophrenia might come from at least three sources: patient-related factors, neuropsychological assessment and treatment effects.

\section{Patient-related factors}

The pattern of cognitive impairment in patients with schizophrenia is likely to be a function of the heterogeneity within the disorder itself. ${ }^{37}$ To homogenise the population as much as possible for differences in illness-phase, ${ }^{38}$ we only included drug-naive patients with a first episode. Moreover, based on the current lack of definitive validation for any psychosis subtype, ${ }^{39}$ we chose a broad approach by including schizophrenia-spectrum disorders. Nevertheless, the analysis from the statistical procedures performed only on patients with schizophrenia demonstrated that there were no great differences compared with the entire sample.

One of the most important determinants of neuropsychological performance is premorbid scholastic performance. Premorbid intra-individual intellectual performance variability has been associated with the risk of developing schizophrenia, ${ }^{40}$ and low premorbid intellectual achievement may also be an early manifestation of the illness. ${ }^{41} \mathrm{New}$ to this study was that lower premorbid IQ predicted cognitive improvement over 6 months. This implies that patients with greater 'cognitive reserve', who are already experiencing cognitive changes related to schizophrenia, perform within normal limits until acute impairment is severe. Likewise, patients with lower cognitive reserve are less able to compensate for cognitive deficits; consequently, they are prone to develop greater cognitive dysfunction related to the acute episode and show a wider range of intraindividual variability on standard clinical cognitive testing.

\section{Neuropsychological issues in the assessment of cognitive improvement}

Accurate interpretations of the neuropsychological test findings are based on the premise that each test is reasonably free of measurement error, practice effects and that tests are not prone to floor and ceiling effects. In our study, the reliable change index method (both simple and practice) was used as a statistical technique to account for the reliability of intra-individual score changes. As was reported for patients with stable schizophrenia, ${ }^{42}$ we found larger-than-expected percentages of patients with schizophrenia-spectrum disorders classified as cognitively changed on 6-month retest assessments. In this regard, although reliable change index methods allowed us to delineate cut-off points for cognitive improvement in neuropsychological tests, cognitive decline and cognitively stable patterns are better interpreted as 'lower performance than predicted'. Moreover, after inspection of the baseline and 6-month plots of our 14 neuropsychological measures, we determined that our results were not subject to floor or ceiling effects.

\section{Antipsychotic drug effects on cognitive performance}

There were no significant differences in cognitive effectiveness among the four treatment groups over the 6 months of treatment. These results added support to studies reporting that atypical antipsychotic drugs produced significant improvement in neurocognition, ${ }^{16,43,44}$ although with a smaller effect than previously reported. $^{7,17}$

To account for practice effects ${ }^{19}$ we did not include a healthy control group but we employed differences in neuropsychological tests between the 1-month assessment, when patients were clinically stable, and the 6-month assessment to derive our RCI-p. The latter is in agreement with the findings of Heaton et $a l,{ }^{42}$ who found large standard errors in patients with schizophrenia, suggesting that results from normative populations might not be appropriate for them. The RCI-p and RCI-s results were similar, and nearly a half of our patients with schizophreniaspectrum disorders (47.29 and 45.83\%, RCI-s and RCI-p respectively) showed an improvement in GCS, irrespective of treatment allocation.

Moreover, since cognitive improvement was not only seen on tests more prone to practice effect - such as those involving a large speed component, requiring an infrequently practised response or those involving learning ${ }^{45}$ - it seemed feasible in all 14 neuropsychological measures that cognitive improvement was not only due to practice, but was also a direct drug effect. There could also be an effect of the 'acute episode', but linear estimations by means of multiple regressions showed that variations in psychopathological syndrome scores only accounted for a small amount of the explained variance and not in all neuropsychological measures (Table 3). It seems unlikely that a placebo effect would only show an improvement between baseline and the 1-month assessment; however, it showed an effect that lasted for 6 months, even for the no-antipsychotic group and in a naturalistic setting.

An unexpected finding of our study was the lack of great differences in cognitive improvement between patients receiving atypical antipsychotic drugs and patients without antipsychotic drugs after the first 3 months of follow-up. This finding suggests that cognitive enhancement related to antipsychotic drugs in patients with first-episode schizophrenia-spectrum disorder might be apparent in the first weeks of treatment and might last for at least 6 months, irrespective of subsequent treatment.

\section{Relevance of cognitive impairment at baseline for cognitive improvement}

Individual improvement for each neuropsychological measure on the basis of RCI methods revealed that the higher the cognitive impairment at baseline assessment, the greater the rate of improvement with treatment. However, when individual profiles were compared between patients who showed improvement and worsening on the RCI, we discovered a limitation to this method: 
those who began with high scores could not demonstrate improvement because of a ceiling effect related to the capacity of being able to improve on neuropsychological tests beyond normal limits. These patients performing well at the beginning continued doing well during follow-up, and as a consequence, their cognitive change was clearly inferior to those starting at very low levels of performance.

The insight gleaned from our results will help guide future studies, which should be focused at the individual level in order to differentiate any potential factors contributing to the cognitive heterogeneity of our patients. Moreover, an added effort should be made to provide tools for clinicians to interpret and manage changes in cognitive functioning at the individual level such as RCI methods.

\section{Limitations}

Some caution is warranted owing to the small sample in the no-antipsychotic group, which might have led to our study being underpowered to detect real differences on cognitive performance in relation to other treatment groups. However, ANCOVA has been repeatedly demonstrated to be one of the most powerful methods of analysis for randomised comparative trials ${ }^{46}$ and statistical power usually increases with repeated measures designs in situations where large individual differences are expected. ${ }^{47}$

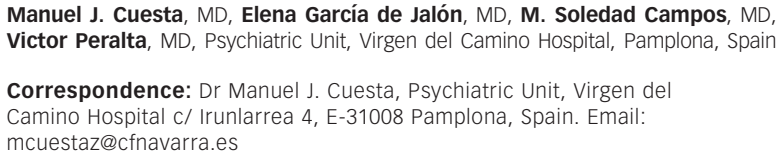

\section{Funding}

The Navarrás Government provided funding for implementation of the study (grants 946 2005 and 55/2007).

\section{Acknowledgements}

We thank all participants and support staff that made this study possible. We are also grateful to Manel Salamero for his advice on statistical analysis.

\section{References}

1 Heinrichs RW, Zakzanis KK. Neurocognitive deficit in schizophrenia: a quantitative review of the evidence. Neuropsychology 1998; 12: 426-45.

2 Saykin AJ, Gur RC, Gur RE, Mozley PD, Mozley LH, Resnick SM, et al. Neuropsychological function in schizophrenia. Selective impairment in memory and learning. Arch Gen Psychiatry 1991; 48: 618-24.

3 Cuesta MJ, Peralta V, Caro F, de Leon J. Schizophrenic syndrome and Wisconsin Card Sorting Test dimensions. Psychiatry Res 1995; 58: 45-51.

4 Heaton RK, Gladsjo JA, Palmer BW, Kuck J, Marcotte TD, Jeste DV. Stability and course of neuropsychological deficits in schizophrenia. Arch Gen Psychiatry 2001; 58: 24-32.

5 Kraus MS, Keefe RSE. Cognition as an outcome measure in schizophrenia. Br J Psychiatry 2007; 191 (suppl 50): s46-51.

6 Green MF. What are the functional consequences of neurocognitive deficits in schizophrenia? Am J Psychiatry 1996; 153: 321-30.

7 Green MF. Cognition, drug treatment, and functional outcome in schizophrenia: a tale of two transitions. Am J Psychiatry 2007; 164: 992-4.

8 Cuesta MJ, Peralta V, Zarzuela A. Illness duration and neuropsychological impairments in schizophrenia. Schizophr Res 1998; 33: 141-50.

9 Heaton RK, Crowley TJ. Effects of psychiatry disorders and their somatic treatments on neuropsychological test results. In Handbook of Clinical Neuropsychology (eds SB Filskov, TJ Boll): 481-525. Wiley, 1981.
10 Medalia A, Gold J, Merriam A. The effect of neuroleptics on neuropsychological test results of schizophrenics. Arch Clin Neuropsychol. 1988; 3: 249-71.

11 Spohn HE, Strauss ME. Relation of neuroleptic and anticholinergic medication to cognitive fuctions in schizophrenia. J Abnorm Psychol 1989; 98: 367-80.

12 Cassens G, Inglis AK, Appelbaum PS, Gutheil TG. Neuroleptics: effects on neuropsychological function in chronic schizophrenic patients. Schizophr Bull 1990; 16: 477-99.

13 King DJ. The effect of neuroleptics on cognitive and psychomotor function. $\mathrm{Br}$ J Psychiatry 1990; 157: 799-811.

14 Weickert TW, Goldberg TE. First- and second-generation antipsychotic medication and cognitive processing in schizophrenia. Curr Psychiatry Rep 2005; 7: 304-10.

15 Mishara AL, Goldberg TE. A meta-analysis and critical review of the effects of conventional neuroleptic treatment on cognition in schizophrenia: opening a closed book. Biol Psychiatry 2004; 55: 1013-22.

16 Woodward ND, Purdon SE, Meltzer HY, Zald DH. A meta-analysis of cognitive change with haloperidol in clinical trials of atypical antipsychotics: dose effects and comparison to practice effects. Schizophr Res 2007; 89: 211-24.

17 Keefe RS, Bilder RM, Davis SM, Harvey PD, Palmer BW, Gold JM, et al. Neurocognitive effects of antipsychotic medications in patients with chronic schizophrenia in the CATIE Trial. Arch Gen Psychiatry 2007; 64: 633-47.

18 Sharma T. Cognitive effects of conventional and atypical antipsychotics in schizophrenia. Br J Psychiatry 1999; 174 (suppl 38): s44-51.

19 Goldberg TE, Goldman RS, Burdick KE, Malhotra AK, Lencz T, Patel RC, et al. Cognitive improvement after treatment with second-generation antipsychotic medications in first-episode schizophrenia: is it a practice effect? Arch Gen Psychiatry 2007; 64: 1115-22.

20 American Psychiatric Association. Diagnostic and Statistical Manual of Mental Disorders (4th edn, text revision) (DSM-IV-TR). APA, 2000.

21 Andreasen NC, Flaum M, Arndt S. The Comprehensive Assessment of Symptoms and History (CASH). An instrument for assessing diagnosis and psychopathology. Arch Gen Psychiatry 1992; 49: 615-23.

22 Woods SW. Chlorpromazine equivalent doses for the newer atypical antipsychotics. J Clin Psychiatry 2003; 64: 663-67.

23 Osterberg L, Blaschke T. Adherence to medication. N Engl J Med 2005; 353 487-97.

24 Reitan RM, Wolfson D. The Halstead-Reitan Neuropsychological Test Battery: Theory and Clinical Interpretation. Neuropsychology Press, 1985.

25 wechsler DA. Standarized memory scale for clinical use. J Psychology 1945; 19: 87-95.

26 Spaulding W, Garbin CP, Dras SR. Cognitive abnormalities in schizophrenic patients and schizotypal college students. J Nerv Ment Dis 1989; 177 717-28.

27 Penn DL, Van Der Does W, Spaulding W, Garbin CP, Linszen D, et al Information processing and social cognitive problem solving in schizophrenia. J Nerv Ment Dis 1993; 181: 13-20.

28 Hair JF, Black B, Babin B, Anderson RE, Tatham RL. Multivariate Data Analysis (6th edn). Pearson Prentice Hall, 2005.

29 Brown L, Sherbenou RJ, Johnsen SK. TONI-2 Test de Inteligencia No Verbal. TEA Ediciones, 1995

30 Jacobson NS, Truax P. Clinical significance: a statistical approach to defining meaningful change in psychotherapy research. J Consult Clin Psychol 1991; 59: 12-9.

31 Saykin AJ, Shtasel DL, Gur RE, Kester DB, Mozley LH, Stafiniak P, et al. Neuropsychological deficits in neuroleptic naive patients with first-episode schizophrenia. Arch Gen Psychiatry 1994; 51: 124-31.

32 Bilder RM, Goldman RS, Robinson D, Reiter G, Bell L, Bates JA, et al. Neuropsychology of first-episode schizophrenia: initial characterization and clinical correlates. Am J Psychiatry 2000; 157: 549-59.

33 Lee SM, Chou YH, Li MH, Wan FJ, Yen MH. Effects of antipsychotics on cognitive performance in drug-naive schizophrenic patients. Prog Neuropsychopharmacol Biol Psychiatry 2007; 31: 1101-7.

34 Townsend LA, Norman RM. Course of cognitive functioning in first episode schizophrenia spectrum disorders. Expert Rev Neurother 2004; 4: 61-8.

35 Mohamed S, Paulsen JS, O'Leary D, Arndt S, Andreasen N. Generalized cognitive deficits in schizophrenia: a study of first-episode patients. Arch Gen Psychiatry 1999; 56: 749-54.

36 Riley EM, McGovern D, Mockler D, Doku VC, OCeallaigh S, Fannon DG, et al. Neuropsychological functioning in first-episode psychosis - evidence of specific deficits. Schizophr Res 2000; 43: 47-55.

37 Goldstein G, Shemansky WJ. Influences on cognitive heterogeneity in schizophrenia. Schizophr Res 1995; 18: 59-69. 
38 González-Blanch C, Alvarez-Jiménez M, Rodríguez-Sánchez JM, Pérez-Iglesias R, Vázquez-Barquero JL, Crespo-Facorro B. Cognitive functioning in the early course of first-episode schizophrenia spectrum disorders: timing and patterns. Eur Arch Psychiatry Clin Neurosci 2006; 256 364-71.

39 Peralta V, Cuesta MJ. A dimensional and categorical architecture for the classification of psychotic disorders. World Psychiatry 2007; 6: 36-7.

40 Reichenberg A, Weiser M, Rapp MA, Rabinowitz J, Caspi A, Schmeidler J, et al Pre-morbid intra-individual variability in intellectual performance and risk for schizophrenia: a population-based study. Schizophr Res 2006; 85: 49-57.

41 Cannon M, Caspi A, Moffit TE, Harrington H, Taylor A, Murray RM, et al. Evidence for early-childhood, pan-developmental impairment specific to schizophreniform disorder: results from a longitudinal birth cohort. Arch Gen Psychiatry 2002; 59: 449-56.

42 Heaton RK, Temkin N, Dikmen S, Avitable N, Taylor MJ, Marcotte TD, et al. Detecting change: a comparison of three neuropsychological methods, using normal and clinical samples. Arch Clin Neuropsychol 2001; 16: 75-91.
43 Keefe RS, Sweeney JA, Gu H, Hamer RM, Perkins DO, McEvoy JP, et al. Effects of olanzapine, quetiapine, and risperidone on neurocognitive function in early psychosis: a randomized, double-blind 52-week comparison. Am J Psychiatry 2007; 164: 1061-71.

44 Cuesta MJ, Peralta V, Zarzuela A. Effects of olanzapine and other antipsychotics on cognitive function in chronic schizophrenia: a longitudinal study. Schizophr Res 2001; 48: 17-28.

45 Lezak MD. Neuropsychological Assessment (3rd edn). Oxford University Press, 1995.

46 Vickers AJ. How many repeated measures in repeated measures designs? Statistical issues for comparative trials. BMC Med Res Methodol 2003; 3: 22

47 Allison DB, Allison RL, Faith MS, Paultre F, Pi-Sunyer FX. Power and money: designing statistically powerful studies while minimizing financial costs. Psychol Methods 1997; 2: 20-33.

\section{Psychiatrists in 19th-century fiction}

\section{Armadale (1866), Wilkie Collins}

\section{Fiona Subotsky}

Lunatic asylums appear in other novels of Wilkie Collins, notably The Woman in White and Jezebel's Daughter, but their medical attendants are not significant for the stories. The villainous Dr Le Doux of Armadale makes up for this. He is represented as not only foreign (suspicious in itself) but unqualified; he has previously practised under another name as an abortionist. Collins can thus distance himself from medical criticism.

Wilkie Collins (1824-1889) largely wrote 'sensation' novels, with a strong element of suspense, rather than the clearly supernatural; however, 'gothic' motifs are readily recognisable. For instance, the approach to Dr Le Doux's Sanatorium in Hampstead is described thus:

'The day was overcast, and the place looked very dreary ... at one corner of this scene of desolation stood a great overgrown dismal house, plastered with drab-coloured stucco, and surrounded by a naked, unfinished garden, without a shrub or flower in it - frightful to behold... The pallid withered old manservant in black, who answered the door, looked as if he had stepped up out of his grave to perform that service . . . I shivered as I crossed the threshold.'

Dr Le Doux has set up his new asylum as a money-making venture and has sent an invitation for a tour to the local population. Inside, by way of advertisement, he has a 'collection of photographic portraits of men and women' illustrating separately 'the effects of nervous suffering' and 'the ravages of insanity ... while the space between was occupied by an elegantly illuminated scroll, bearing inscribed on it the timehonoured motto, "Prevention is better than Cure." ' He also has exhibits serving to underline his (false) scientific credentials and to repel and fascinate the visitors and the readers:

'Horrible objects in brass and leather and glass, twisted and turned as if they were sentient things writhing in agonies of pain ... shapeless dead creatures of a dull white colour floated in yellow liquid'.

The doctor is also a master of technology, with the very latest in provision and gadgetry for the comfort and treatment of his patients, notably the ventilation method, which he is later persuaded to put to deadly use:

'The asthmatic nervous patient gasps with terror at the idea of a chemical explosion in his room. I noiselessly fumigate one of them; I noiselessly oxygenize the other, by means of a simple apparatus fixed outside in the corner here. It is protected by this wooden casing; it is locked with my own key; and it communicates by means of a tube with the interior of the room. Look at it!'

In league with the evil Miss Gwilt, Dr Le Doux's plan is to trick the hero Armadale into staying, and then kill him. Subsequently, he intends to declare Armadale to have been deluded and 'certify his brain to have been affected by one of those mysterious disorders, eminently curable, eminently fatal'. The doctor is extremely well informed about the regulations of his day. 'This is not a mad-house; this is not a licensed establishment; no doctors' certificates are necessary here!' Later, however, he anxiously reflects that:

'A note may be smuggled out of the house, and may reach the Commissioners in Lunacy. Even in the case of an unlicensed establishment like mine, those gentlemen - no! those chartered despots in a land of liberty - have only to apply to the Lord Chancellor for an order, and to enter (by heavens, to enter My Sanatorium!) and search the house from top to bottom at a moment's notice!'

Suffice it to say that the plan does not work out as expected, and Miss Gwilt is found dead, possibly from an apoplexy. The epilogue comprises a letter from the family solicitor, who suspects Dr Le Doux of a great deal, but nothing can be proved. Indeed, his friends and admirers are about to present him with a Testimonial expressing sympathy. The solicitor concludes ruefully that: 'In this enlightened nineteenth century, I look upon the doctor as one of our rising men'. 